ROBERT KOCH INSTITUT

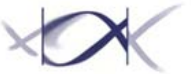

Originally published as:

Neuhauser, H.K., Lempert, T.

Vertigo: Epidemiologic aspects

(2009) Seminars in Neurology, 29 (5), pp. 473-481

DOI: $10.1055 / \mathrm{s}-0029-1241043$

The definitive version is available at: www.thieme-connect.com 


\title{
Vertigo: Epidemiologic Aspects
}

\author{
Hannelore K. Neuhauser, M.D., M.P.H., ${ }^{1,2}$ and Thomas Lempert, M.D. ${ }^{2,3}$ \\ ${ }^{1}$ Department of Epidemiology, Robert Koch Institute, Berlin, Germany \\ 'Department of Neurology, Vestibular Research Group, Charite', Berlin, Germany \\ ${ }^{3}$ Department of Neurology, Schlosspark-Klinik, Berlin, Germany
}

\begin{abstract}
Vertigo is a frequent symptom in the general population with a 12-month prevalence of $5 \%$ and an incidence of $1.4 \%$ in adults. Its prevalence rises with age and is about two to three times higher in women than in men. The epidemiology of vertigo and underlying specific vestibular disorders is still an underdeveloped field despite its usefulness for clinical decision making and its potential for improving patient care. In this article, the authors give an overview on the epidemiology of vertigo as a symptom and of four specific vestibular disorders: benign paroxysmal positional vertigo (BPPV), vestibular migraine, Ménière's disease, and vestibular neuritis.
\end{abstract}

Epidemiologic data on vertigo and on specific vestibular syndromes are used for evidence-based clinical decision making, 1 and are therefore valuable for clinicians and not only for public health experts. Furthermore, the investigation of vestibular disorders in the larger context of populations can contribute to a better understanding of causative factors, unravel unbiased information on outcome and prognosis, and point toward problems in the delivery of care. In addition, unselected vertigo patients from epidemiologic studies may be much more similar to the patients seen by most neurologists than are the highly selected patients from Dizziness Clinic case series. Finally yet importantly, epidemiologic data on risk factors for vestibular disorders can help generate new pathophysiologic hypotheses and may ultimately help improve therapy.

Data on the epidemiology of vertigo, however, are scarce; one of the underlying reasons is that vertigo is a subjective symptom and difficult to define. The Hearing and Equilibrium Committee of the American Academy of Otolaryngology-Head and Neck Surgery has defined vertigo as "the sensation of motion when no motion is occurring relative to earth's gravity."2 Although patients and many physicians tend to use the terms vertigo and dizziness interchangeably, dizziness experts seek to differentiate vertigo-as a symptom that arises from the vestibular system-from nonvestibular dizziness, which can comprise a sensation of light-headedness, giddiness, unsteadiness, drowsiness, or impeding faint. In this

article, we use the term vertigo as a vestibular symptom. As measures of disease frequency in the population we use incidence (proportion of newly developed — incident-disease over a specific period) and prevalence (proportion of an existing disease at one time point, point prevalence, or during a given period, period prevalence, e.g., one-year prevalence). Lifetime prevalence denotes the cumulative lifetime frequency of a disease to the present time, i.e., the proportion of people who have had the event at any time in the past.

This review will focus on the frequency and distribution of the vestibular symptom vertigo, and of four specific vestibular disorders, and will report recent findings on associated risk factors and personal and health care impact.

\section{Epidemiology of Vertigo}

The epidemiology of vertigo as a symptom reveals the true size and distribution of the disease burden caused by vestibular disorders. This disease burden would be largely underestimated if we would merely add up the data available on specific vestibular diagnoses, the most frequent of which are largely underdiagnosed, such as benign paroxysmal positional vertigo (BPPV) and vestibular migraine.3-6 


\section{Prevalence, Incidence, and Demographic Factors}

Dizziness (including vertigo and nonvestibular dizziness) ranks among the most common complaints in medicine, affecting _20 to 30\% of the general population.7-9 Surprisingly, rotatory dizziness, which may be interpreted as vertigo, has also been reported in up to 20 to $30 \%$ of adults in population-based questionnaire studies,8-10 but various methodologic factors may lead to this high prevalence, including suggestibility of a rotatory sensation and lack of a defined threshold (Should "a little dizzy" be counted as dizzy?). The question how frequent vestibular vertigo is at the population level was answered recently by means of a population survey by validated neurotologic interviews performed in Germany.11 This study combined a screening of a representative National Health Survey general population sample $\left(n^{1 / 44,869)}\right.$ for moderate or severe dizziness or vertigo with detailed validated neurotologic interviews ( $\mathrm{n}^{1 / 41003)}$, which included an interactive part similar to a clinical situation and detailed standardized questions. Each participant was classified by at least two raters. Vestibular vertigo was defined as rotational vertigo (illusion of self-motion or object motion), positional vertigo (vertigo or dizziness precipitated by changes of head position, such as lying down or turning in bed) or recurrent dizziness with nausea and oscillopsia or imbalance. The lifetime prevalence of vertigo in adults aged 18 to 79 was $7.4 \%$, the one-year prevalence $4.9 \%$, and the one-year incidence $1.4 \%$ (Table 1). Vestibular vertigo accounted for almost a quarter (24\%) of dizziness/vertigo cases in the community. The study confirmed previous findings of a marked female preponderance among individuals with vertigo (one-year prevalence ratio male to female 1:2.7), and showed that vertigo is almost three times more frequent in the elderly compared with the young (Fig. 1).

\section{Personal and Occupational Impact of Vertigo}

Vertigo has a considerable personal impact. In the epidemiologic study from Germany described above, vertigo was recurrent in the vast majority of participants (88\%) and caused severe impairment in $80 \%$ of affected individuals (i.e., it resulted in an interruption of daily activities, sick leave, or medical consultation). In addition, participants with vestibular vertigo had a lower ageand sex-adjusted healthrelated quality of life compared with vertigo- and dizziness-free participants.12 Vertigo can cause psychiatric problems, which do not necessarily correlate with deficits on neurotologic testing. In a recent study, patients with vestibular neuritis and persistent vestibular deficits had lower levels of anxiety, depression, and somatization than patients with Ménière's disease or vestibular migraine.13 Of note, comorbid psychiatric symptoms in patients with organic otoneurologic disorders should be differentiated from somatoform otoneurologic symptoms, which include somatoform dizziness.14

Little is known about the occupational impact of vertigo. Sick leave due to vestibular vertigo was reported by $41 \%$ of participants with vestibular vertigo working at the time, and by $15 \%$ of those with nonvestibular dizziness in a population-based study.12 In employees on long-term sick leave (more than 8 weeks), dizziness/ vertigo was a rather infrequent cause $(0.9 \%$ of women and $0.7 \%$ of men) in a register-based prospective study from Norway.15 This corresponds to an annual incidence for women of 7.5 in 10,000 at risk (vocationally active) and for men of 3.2 in 10,000 at risk. One quarter of these women and men obtained a disability pension. However, most recurrent but nonchronic vertigo is unlikely to cause such long episodes of sickness leave, and the occupational impact of repeated short-term absence or more subtle productivity loss is unknown.

\section{Health Care Impact of Vertigo}

Vertigo and dizziness rank among the 10 most common reasons for referral to neurologists both in emergency rooms 16 and in office-based settings.17 In the German neurotologic survey, vestibular vertigo accounted for $29 \%$ of dizziness/vertigo cases seen by a doctor. Overall, $70 \%$ of vertigo sufferers consulted a physician; however, more than half of participants with clear-cut vestibular vertigo were diagnosed with a nonvestibular disorder. 12 The study also showed that $0.9 \%$ of unselected adults consulted a physician in the last 12 months for incident vestibular vertigo, that is for a new symptom that often leads to a costly diagnostic workup.12 Similarly, a recent Spanish primary care study found 7.6 per 1000 inhabitants (i.e., $0.8 \%$ ) consulted in primary care over 12 months for incident vertigo defined as an illusion of unequivocal rotatory movement.18 The prevalence of primary care consultations for combined incident and recurrent vertigo was 1.8\% over 12 months in the Spanish study. 
However, specific diagnoses are documented only rarely in dizziness/vertigo patients seen in primary care: more than $80 \%$ of 10,000 patients from a German primary care database were coded only as a symptom and not as specific diagnoses. Only $3.9 \%$ of dizziness/

vertigo patients were referred to specialists.19 Claims that dizziness/vertigo is a nonspecific symptom in a high proportion of patients, especially in old age, have been convincingly contradicted, for example, by a recent study showing that out of 3400 patients over 70 years of age an accurate diagnosis was possible in more than $75 \%$. In these elderly patients, dizziness often had a multifactorial etiology and caused age-specific impairment, but dizziness caused by age per se was not found.20

Dizziness and vertigo account for an increasing proportion of visits to emergency departments (ED), currently amounting to 2 to $3 \%$ of all consultations.21,22 In this setting, identification of central or otherwise serious vertigo is a major concern.22,23 However, stroke was found to be a rare cause of dizziness presentations to the ED in a recent population-based stroke surveillance study: only $0.7 \%$ of those presenting with isolated dizziness and $3.2 \%$ of those presenting with any dizziness had an acute cerebrovascular cause. 24 In EDs in the United States, where nearly 26 million ED visits for dizziness/ vertigo over a period of 10 years (1995-2004) have been estimated, a median of 3.6 diagnostic tests per patient were performed and $17 \%$ of patients had a computed tomography (CT) scan or magnetic resonance imaging (MRI).21 In summary, data from primary care and from EDs show that misdiagnosis of vertigo and dizziness is common,3-6,25 and suggest that appropriate training for these disorders may benefit patients and save costs.

\section{Risk Factors for Vertigo}

Vertigo can be a symptom of a variety of conditions with different etiologies. Therefore, the potential benefit of investigating risk factors for the symptom vertigo is limited, and findings must be interpreted cautiously. However, some interesting insights have resulted from such studies, the most prominent being the consistent association of vertigo and migraine,26-28 which has greatly contributed to the recognition of vestibular migraine as a distinct vestibular syndrome. Migraine is also statistically associated with BPPV29-31 and Ménière's disease.32 However, the implications of these associations are not clear yet. Because migraine is more common in women, the association of migraine and specific vestibular disorders may partly explain the marked female preponderance among vertigo sufferers, which has also been consistently reported for specific vestibular disorders including BPPV,33 Me' nie 're's disease,32 and vestibular migraine.28 Along that line, case series have suggested that premenstrual or drug-related hormonal changes may increase the risk of vestibular disorders, 34,35 but this was not confirmed by two other large studies.11,36

There is increasing evidence for an association of vertigo with depression11,37,38; however, the directionality of this association is not clear yet. A structured evaluation of 100 randomly selected communitydwelling individuals with vertigo showed a $20 \%$ prevalence of depressive symptoms. $39 \mathrm{~A}$ recent study found that a previous psychiatric disorder is a strong predictor for the development of reactive psychiatric disorders in vestibular patients. $40 \mathrm{~A}$ few studies suggest a link between vertigo and cardiovascular risk factors (for a summary, see Neuhauser et al11), but the evidence is insufficient to support an independent association in unselected individuals after taking potential confounders into account. Of note, overt cardiovascular disease was not significantly associated with vertigo after correcting for potential confounders.11 In particular, transient ischemic attacks (TIAs) and stroke presenting with monosymptomatic vertigo are rare at the population level.41

\section{Epidemiology of Vestibular Disorders}

Due to scarce epidemiologic data, it may be tempting to extrapolate the distribution and outcome of vestibular disorders from studies in specialized care settings. However, this approach may be misleading and has been compared with the story where several blind men feel a different part of an elephant's body and each one gives an accurate but biased account about what the elephant is like.42 For example, the relative frequency of Ménière's disease of 5 to $11 \%$ in specialized care settings $28,43,44$ is almost certainly due to selection bias, and considerably overestimates the prevalence in the community. 


\section{Benign Paroxysmal Positional Vertigo}

Benign paroxysmal positional vertigo deserves special attention among vestibular disorders because it is not only the most frequent cause of recurrent vertigo, but it is also amenable to successful and inexpensive treatment by liberatory maneuvers. 45 However, the importance of BPPV at the population level is still underestimated due to low recognition rates in primary care3,6 and scarce epidemiologic data. Two older studies that estimated the incidence of BPPV at $0.01 \%$ in Japan46 and $0.06 \%$ in Olmsted County, Minnesota, 47 were based on recorded clinical cases and thus likely to considerably underestimate the incidence at the population level. A strikingly higher finding of $9 \%$ positive DixHallpike tests in a series of 100 geriatric clinic patients suggested that BPPV may be much more common in the community than previously thought. 48 In a recent study of 38 unselected patients with a diagnosis of "dizziness" in primary care consultation, $40 \%$ had both typical symptoms of BPPV and a positive Dix-Hallpike test.6 Population-based epidemiologic data have been obtained from the nationally representative neurotologic survey conducted in Germany.4 Diagnostic criteria for BPPV were at least five attacks of vertigo lasting less than one minute without concomitant neurologic symptoms and invariably provoked by typical changes of head position (i.e., lying down, turning over in the supine position or at least two of the following maneuvers: reclining the head, rising up from supine position, and bending forward). The lifetime prevalence of BPPV was estimated at $2.4 \%$, the 1-year prevalence at $1.6 \%$, and the 1-year incidence at $0.6 \%$. Of note, BPPV diagnoses relied on neurotologic interviews and not on positioning maneuvers, but the prevalence estimates are likely to be rather conservative because diagnostic criteria emphasized specificity and not sensitivity (the interviews had a specificity of $92 \%$ and a sensitivity of $88 \%$ in a concurrent validation study). Benign paroxysmal positional vertigo can manifest from childhood to a very old age with a reported peak age of onset in the sixth decade for idiopathic BPPV and a lower mean age of onset in secondary BPPV.49 The one-year prevalence of individuals with BPPV attacks (new-onset and recurrent) rises steeply with age: from $0.5 \%$ in 18 to 39 year olds, to $3.4 \%$ in individuals over 60 years of age. 4 The cumulative (lifetime) incidence of BPPV reaches almost $10 \%$ by the age of $80.4 \mathrm{~A}$ recent clinical study reported a mean spontaneous remission time of untreated BPPV episodes of 39 days for posterior canal BPPV and 16 days for horizontal canal BPPV,50 a difference that is linked to the anatomic orientation of the canals. In the community, however, untreated episodes appear to be shorter, as suggested by a median episode duration of 2 weeks among 80 mostly untreated community-sampled individuals with BPPV (this study did not differentiate the affected canals). 4 Most recurrences occur in the first year, and the cumulative recurrence rate is $50 \%$ at 3 to 5 years.51,52 A higher recurrence rate has been reported in traumatic BPPV compared with idiopathic BPPV53 and in women,51 but data on determinants of recurrences are still scarce.

At present, the mechanisms of BPPV may be explained by canalolithiasis and cupulolithiasis. However, the underlying causes that lead to detachment of otoconia from the utricle are still poorly understood in the vast majority of patients. Head trauma and inner ear diseases, such as vestibular neuritis and Ménière's disease, are probably less frequent causes than previously thought, accounting for $6 \%$ of unselected BPPV cases.4,54 More women than men are affected by BPPV (female:male ratio 1.5 to $2.2: 1), 4,33,46$ but this seems to be the case only for idiopathic and not for secondary BPPV.55 This female preponderance is still poorly understood pathophysiologically, but may be linked to an equally poorly understood association of BPPV and migraine.29-31 Osteoporosis, which is more frequent in middle-aged and elderly women with BPPV compared with controls, 56 may also play a role. Recent studies have found associations of BPPV with diabetes57 and with hypertension, hyperlipidemia, and stroke, 4 but these observations await replication.

There is also increasingly more evidence of adverse psychosocial consequences of BPPV, including reduced health-related quality of life, 58 severe subjective impairment in affected individuals, 3,4 and avoidance behavior in $70 \%$ of BPPV sufferers. 4 Medical advice is sought by $80 \%$ of BPPV sufferers, 4 but specific diagnostic positioning maneuvers are applied in less than a third of patients seeking medical care. The rate of adequate therapy is even lower with only 10 to $20 \%$ of BPPV cases seen by a doctor receiving appropriate positioning maneuvers.3,4 


\section{Vestibular Migraine}

Vestibular migraine is the second most common cause of recurrent vertigo after BPPV,28,59 but is only starting to be perceived as a nosologic entity by the medical community. Various terms, including migraine-associated vertigo, migraine-associated dizziness, migraine-related vestibulopathy, vestibular migraine, and benign recurrent vertigo have all been applied to roughly the same patient population. Vestibular migraine has been convincingly advocated as a term that stresses the particular vestibular manifestation of migraine, and thus best avoids confounding with nonvestibular dizziness or motion sickness associated with migraine. The term basilar migraine is restricted to patients who fulfill the diagnostic criteria of the International Headache Society (IHS)60 for basilar migraine, which applies to only _10\% of patients with vestibular migraine.28,59,61 Interestingly, the awareness of a causal link between vertigo and migraine was promoted by epidemiologic observations indicating a more than chance association of migraine with vertigo and dizziness and not by pathophysiologic hypotheses.26-28,62 Vestibular migraine accounts for 6 to $7 \%$ of patients in neurologic dizziness clinics, 28,59 and has been found in $9 \%$ of patients in a migraine clinic case series.28 Of note, dizziness was reported in over $70 \%$ of consecutive migraineurs, 63 but can have various causes other than vestibular migraine.64 In the general population, migraine headaches and vestibular vertigo concur about three times more often than would be expected by chance. Lifetime prevalences are $14 \%$ for migraine 65 and $7 \%$ for vestibular vertigo.11 Thus, chance concurrence of the two would be $1 \%$, but the German neurotologic survey showed it to be 3.2\%.5 This survey estimated the prevalence of definite vestibular migraine in the general adult population based on validated neurotologic interviews,11 and previously proposed explicit diagnostic criteria28 that require not only a migraine diagnosis according to the International Headache Society criteria, 60 but also that migraine symptoms such as migrainous headache, photophobia, phonophobia, or migrainous auras occur concurrently with spontaneous vertigo attacks. The lifetime prevalence of vestibular migraine was $0.98 \%(95 \% \mathrm{Cl}$ $0.70-1.37)$ and the 12 -month prevalence $0.89(95 \% \mathrm{Cl} 0.62-1.27) .5$ This study did not investigate probable vestibular migraine, which is a more sensitive but less specific diagnostic category than definite vestibular migraine requiring spontaneous vertigo attacks not attributable to another cause, and either a history of migraine or concurrence of migraine symptoms during vertigo.28 An even broader term is benign recurrent vertigo (BRV), 66 which describes recurrent spontaneous attacks of vertigo that do not lead to permanent deficits and which cannot be attributed to a specific cause (other than migraine). The population prevalence of probable vestibular migraine and BRV are not known; however, a recent large case series of 208 patients with BRV comprised 61\% with definite vestibular migraine, $29 \%$ with probable vestibular migraine, and $10 \%$ for which only the broadest term of BRV applied.67 These rates confirm expert opinion that vestibular migraine is a frequent condition both at the population level and in dizziness clinics.

Vestibular migraine may occur at any age.59,61 The prevalence of recurrent vertigo probably related to migraine is estimated at $2.8 \%$ of children between ages 6 and 12.68 Benign paroxysmal vertigo of childhood, an early manifestation of vestibular migraine, is the most common diagnosis in children presenting with vertigo, followed by BPPV.69 In adults with vestibular migraine, there is a clear female preponderance with a reported female-to-male ratio between 1.5 and 5 to $1.28,59,61$ However, a recent study reported that among unselected vestibular migraine sufferers there are not significantly more women than among dizziness-free migraineurs. 5 In most patients, migraine headaches begin earlier in life than vestibular migraine,5,28,59 but little is known about the determinants of vestibular migraine. A comparison of patients with vestibular migraine with dizziness-free migraineurs showed an independent association with coronary heart disease, but not with sex, age, migrainous aura, education, stroke, hypertension, hyperlipidemia, body mass index, or depression. 5

The natural course of vestibular migraine is not well known, but disease severity has been reported to vary over time. 70 However, the impact of vestibular migraine both at the personal and health care level may be considerable, as indicated by lower health-related quality of life scores in vestibular migraine patients compared with dizziness-free controls, 5 higher levels of anxiety and depression in vestibular migraine patients compared with patients with persistent vestibular deficits, 13 and an overall medical consultation rate of almost $70 \%$ among vestibular migraine sufferers. 5 


\section{Vestibular Neuritis}

The scarcity of epidemiologic data on vestibular neuritis, one of the most severely impairing acute vestibular disorders, is remarkable. Vestibular neuritis is likely to be a frequent cause of vertigo because it accounts for 3 to $10 \%$ of diagnoses in specialized dizziness clinics,28,43,71 and was reported to be the second most common dizziness diagnosis in general practice after BPPV.72 However, the only published estimate on the frequency of vestibular neuritis in the general population comes from a government report in Japan, stating that vestibular neuritis occurs in 3.5 per 100,000 inhabitants (although this is not further specified, one can assume that this is a one-year incidence). 73 The methods are not described, but based on the epidemiologic data on other vestibular disorders from this report, considerable underestimation of the frequency of vestibular neuritis in the population is likely. Data of the National Hospital Discharge Registry in Germany document 19,828 cases of vestibular neuronitis in 2006 (www.who.int/classifications/icd/en ), corresponding to 24 per 100,000 inhabitants (personal communication, German National Statistical Office). Also from Japan originates the single largest published series of _600 patients aged 3 to 88 years with a peak of age distribution between 30

and 50 . There was no female preponderance as in other vestibular disorders, but on the contrary, a male predominance until the age of 40.73 The recurrence rate was as low as $1.9 \%$ in a follow-up study with a follow-up period of 5 to 20 years. 74 However, the long-term outcome of vestibular neuritis may not be as favourable as previously thought because persisting dizziness has been reported in 30 to $40 \%$ of patients 75,76 and chronic anxiety in $15 \% .77$ However, complete long-term recovery has been reported in a series of 21 children.78

\section{Ménière's Disease}

Vertigo and cochlear disturbances are common in the general population and when patients present with both, Ménière's disease is frequently suspected. Ménière's disease accounts for 3 to $11 \%$ of diagnoses in dizziness clinics, $28,43,71$ but this reflects selection bias in specialized care settings toward severe, recurrent, and difficult to treat vestibulopathies. In the general population, Me'nie 're's disease is a rare disease; therefore, reliable prevalence and incidence estimates are difficult to obtain. Most studies have been based on patient registers and have various methodological restrictions (for a summary see Kotimäki et al79). A thorough reevaluation of Ménière's disease diagnoses from the Mayo Clinic's Centralized Diagnostic Index in Rochester, according to the previous criteria of the American Academy of Ophthalmology and Otolaryngology (AAOO, 1972), resulted in an estimated annual incidence rate of 15 per 100,000 and a point prevalence of 218 per 100,000 population, which is higher than previous estimates.80 Because Me'nie're's disease is a rare disease, the prevalence is reported per 100,000 population; however, for comparison the estimated 218 per 100,000 correspond to $0.2 \%$, that is eight times less common than BPPV. Furthermore, in the Rochester study, only $65 \%$ had classic Ménière's disease, while $26 \%$ had vestibular Ménière's, and $9 \%$ had cochlear Ménière's, two variants that were included in the 1972 AAOO criteria, but no longer fulfill the 1995 diagnostic criteria for Ménière's disease of the American Academy of Otolaryngology-Head and Neck Surgery (AAO-HNS).2

Recently, a prevalence of 513 per 100,000 was reported from southern Finland, which is considerably higher than figures from previous studies.10 The study was based on a questionnaire sent to a sample of the general population inquiring about vertigo, hearing loss, and tinnitus, and a review of available medical records. The 1995 AAO criteria were used, but the published questionnaire suggests that the hearing loss and duration criteria may have been modified. Interestingly, the number of individuals who reported that they suffer from impaired hearing and tinnitus, and in addition experienced vertigo at some point in the past, was 14 times higher than the number of Ménière's disease cases. This illustrates that when a patient presents with one of the three symptoms of vertigo, hearing loss, and tinnitus, and reports the two others at some point in the past, the probability of Ménière's disease is still rather low and more specific information is required before suspecting Ménière's disease. In medical practice, Ménière's disease is overdiagnosed, as suggested by both the Rochester study and a more recent Finish study, which applied the AAOO and AAO-HNS criteria, respectively, and confirmed only $40 \%$ of Ménière's disease diagnoses suspected in primary care. 79,80

Generally, Ménière's disease is regarded as a disease of the middle-aged, which can occasionally occur in children. However, Ménière's disease is not uncommon after 65 years of age, accounting for $15 \%$ of a large case series. 81 A female preponderance can be assumed based on the data from 
Rochester ( $61 \%$ women) 80 and is confirmed by the latest data from Finland.10 Bilateral disease was present in $19 \%$ in a recent large case series.82 The majority of patients (59\%) with bilateral Ménière's disease developed second-ear symptoms in less than 6 months from onset, but there was also a group with late onset of second ear symptoms (average 14 years, range 1 to 27 years). The debate on the multiple etiologic possibilities of Ménière's disease is ongoing. An intriguing finding is the increased prevalence of migraine in Ménière's disease patients.32 In a recent study, Ménière's disease patients had an earlier onset of symptoms and a greater susceptibility to bilateral hearing loss when they also had migraine.83 However, a frequent occurrence of migrainous symptoms during Ménière's disease attacks has been found, which may reflect some overlap between the diagnostic criteria for Ménière's disease and for vestibular migraine32 or a shared genetic susceptibility. 84 Inhalant and food allergies have been linked with symptoms of Ménière's disease, 85 but the evidence is not conclusive.

\section{Conclusion}

Epidemiologic findings on the distribution, determinants, and outcome of vertigo can contribute both to better patient care and to a better understanding of the underlying causes of vestibular disorders. Epidemiologic observations of the association between migraine and vertigo are a good example. However, the epidemiology of vertigo and vestibular disorders is still an underdeveloped field. In particular, prevalence and outcome studies are frequently hampered by selection bias due to patient identification in specialized care settings. Recent studies have underscored the high frequency and impact of the symptom vertigo and of vestibular disorders at the population level, in particular BPPV and vestibular migraine, but the determinants and outcome of these frequent conditions are not well known yet.

\section{References}

1. Lurie JD, Sox HC. Principles of medical decision making. Spine 1999;24(5):493-498

2. Committee on Hearing and Equilibrium. Committee on Hearing and Equilibrium guidelines for the diagnosis and evaluation of therapy in Meniere's disease. Otolaryngol Head Neck Surg 1995;113(3):181-185

3. von Brevern M, Lezius F, Tiel-Wilck K, Radtke A, Lempert T. Benign paroxysmal positional vertigo: current status of medical management. Otolaryngol Head Neck Surg 2004; 130(3):381-382

4. von Brevern M, Radtke A, Lezius F, et al. Epidemiology of benign paroxysmal positional vertigo: a population based study. J Neurol Neurosurg Psychiatry 2007;78(7):710-715

5. Neuhauser HK, Radtke A, von Brevern M, et al. Migrainous vertigo: prevalence and impact on quality of life. Neurology 2006;67(6):1028-1033

6. Ekvall Hansson E, Ma ${ }^{\circ}$ nsson NO, $\mathrm{Ha}^{\circ}$ kansson A. Benign paroxysmal positional vertigo among elderly patients in primary health care. Gerontology 2005;51(6):386-389

7. Kroenke K, Price RK. Symptoms in the community. Prevalence, classification, and psychiatric comorbidity. Arch Intern Med 1993;153(21):2474-2480

8. Yardley L, Owen N, Nazareth I, Luxon L. Prevalence and presentation of dizziness in a general practice community sample of working age people. Br J Gen Pract 1998;48(429): 1131-1135

9. Hannaford PC, Simpson JA, Bisset AF, Davis A, McKerrow W, Mills R. The prevalence of ear, nose and throat problems in the community: results from a national cross-sectional

postal survey in Scotland. Fam Pract 2005;22(3):227-233

10. Havia M, Kentala E, Pyykköl. Prevalence of Ménière's disease in general population of Southern Finland. Otolaryngol Head Neck Surg 2005;133(5):762-768

11. Neuhauser HK, von Brevern M, Radtke A, et al. Epidemiology of vestibular vertigo: a neurotologic survey of the general population. Neurology 2005;65(6):898-904

12. Neuhauser HK, Radtke A, von Brevern M, Lezius F, Feldmann M, Lempert T. Burden of dizziness and vertigo in the community. Arch Intern Med 2008;168(19):2118-2124

13. Best C, Eckhardt-Henn A, Diener G, Bense S, Breuer P, Dieterich M. Interaction of somatoform and vestibular disorders. J Neurol Neurosurg Psychiatry 2006;77(5):658- 664

14. Eckhardt-Henn A, Dieterich M. Psychiatric disorders in otoneurology patients. Neurol Clin 2005;23(3):731-749, vi

15. Skøien AK, Wilhemsen K, Gjesdal S. Occupational disability caused by dizziness and vertigo: a register-based prospective study. Br J Gen Pract 2008;58(554):619-623 
16. Moulin T, Sablot D, Vidry E, et al. Impact of emergency room neurologists on patient management and outcome. Eur Neurol 2003;50(4):207-214

17. Schappert SM, Nelson C. National Ambulatory Medical Care Survey, 1995-96 Summary. National Center for Health Statistics. Vital Health Stat 13 1999;142:1-122

18. Garrigues HP, Andres C, Arbaizar A, et al. Epidemiological aspects of vertigo in the general population of the autonomic region of Valencia, Spain. Acta Otolaryngol 2008;128(1): 43-47

19. Kruschinski C, KerstingM, Breull A, Kochen MM, Koschack J, Hummers-Pradier E. [Frequency of dizziness-related diagnoses and prescriptions in a general practice database]. Z Evid Fortbild Qual Gesundhwes 2008;102(5):313-319

20. Katsarkas A. Dizziness in aging: the clinical experience. Geriatrics 2008;63(11):18-20

21. Kerber KA, Meurer WJ, West BT, Fendrick AM. Dizziness presentations in U.S. emergency departments, 1995-2004. Acad Emerg Med 2008;15(8):744-750

22. Newman-Toker DE, Hsieh YH, Camargo CA Jr, Pelletier AJ, Butchy GT, Edlow JA. Spectrum of dizziness visits to US emergency departments: cross-sectional analysis from a nationally representative sample. Mayo Clin Proc 2008;83(7): 765-775

23. Eagles D, Stiell IG, Clement CM, et al. International survey of emergency physicians' priorities for clinical decision rules. Acad Emerg Med 2008;15(2):177-182

24. Kerber KA, Brown DL, Lisabeth LD, Smith MA, Morgenstern LB. Stroke among patients with dizziness, vertigo, and imbalance in the emergency department: a population-based study. Stroke 2006;37(10):2484-2487

25. Moeller JJ, Kurniawan J, Gubitz GJ, Ross JA, Bhan V. Diagnostic accuracy of neurological problems in the emergency department. Can J Neurol Sci 2008;35(3):335-341

26. Kuritzky A, Ziegler DK, Hassanein R. Vertigo, motion sickness and migraine. Headache 1981;21(5):227-231

27. Kayan A, Hood JD. Neuro-otological manifestations of migraine. Brain 1984;107(Pt 4):1123-1142

28. Neuhauser $\mathrm{H}$, Leopold $\mathrm{M}$, von Brevern M, Arnold G, Lempert T. The interrelations of migraine, vertigo, and migrainous vertigo. Neurology 2001;56(4):436-441

29. Ishiyama A, Jacobson KM, Baloh RW. Migraine and benign positional vertigo. Ann Otol Rhinol Laryngol 2000;109(4): 377-380

30. Lempert T, Leopold M, von Brevern M, Neuhauser $\mathrm{H}$. Migraine and benign positional vertigo. Ann Otol Rhinol Laryngol 2000;109(12 Pt 1):1176

31. Uneri A. Migraine and benign paroxysmal positional vertigo: an outcome study of 476 patients. Ear Nose Throat J 2004; 83(12):814-815

32. Radtke A, Lempert T, Gresty MA, Brookes GB, Bronstein AM, Neuhauser H. Migraine and

Me'nie 're's disease: is there a link? Neurology 2002;59(11):1700-1704

33. Katsarkas A. Benign paroxysmal positional vertigo (BPPV): idiopathic versus post-traumatic. Acta Otolaryngol 1999; 119(7):745-749

34. Rybak LP. Metabolic disorders of the vestibular system. Otolaryngol Head Neck Surg 1995;112(1):128-132

35. Andrews JC, Ator GA, Honrubia V. The exacerbation of symptoms in Menie're's disease during the premenstrual period. Arch Otolaryngol Head Neck Surg 1992;118(1):74- 78

36. Vessey $M$, Painter R. Oral contraception and ear disease: findings in a large cohort study.

Contraception 2001;63(2): 61-63

37. Monzani D, Casolari L, Guidetti G, Rigatelli M. Psychological distress and disability in patients with vertigo. J Psychosom Res 2001;50(6):319-323

38. Grunfeld EA, Gresty MA, Bronstein AM, Jahanshahi M. Screening for depression among neurootology patients with and without identifiable vestibular lesions. Int J Audiol 2003; 42(3):161-165

39. Ketola S, Havia M, Appelberg B, Kentala E. Depressive symptoms underestimated in vertiginous patients. Otolaryngol Head Neck Surg 2007;137(2):312-315

40. Best C, Eckhardt-Henn A, Tschan R, Dieterich M. Psychiatric morbidity and comorbidity in different vestibular vertigo syndromes. Results of a prospective longitudinal study over one year. J Neurol 2009;256(1):58-65

41. Rathore SS, Hinn AR, Cooper LS, Tyroler HA, Rosamond WD. Characterization of incident stroke signs and symptoms: findings from the atherosclerosis risk in communities study. Stroke 2002;33(11):2718-2721

42. Sloane PD, Dallara J. Clinical research and geriatric dizziness: the blind men and the elephant. J Am Geriatr Soc 1999;47(1):113-114

43. Brandt T. A chameleon among the episodic vertigo syndromes: 'migrainous vertigo' or 'vestibular migraine'. Cephalalgia 2004;24(2):81-82

44. Guilemany JM, Martı́nez P, Prades E, Sañudo I, De España R, Cuchi A. Clinical and epidemiological study of vertigo at an outpatient clinic. Acta Otolaryngol 2004;124(1):49-52 
45. Bronstein AM. Benign paroxysmal positional vertigo: some recent advances. Curr Opin Neurol 2003;16(1):1-3 46. Mizukoshi K, Watanabe Y, Shojaku H, Okubo J, Watanabe I. Epidemiological studies on benign paroxysmal positional vertigo in Japan. Acta Otolaryngol Suppl 1988;447:67-72 47. Froehling DA, Silverstein MD, Mohr DN, Beatty CW, Offord KP, Ballard DJ. Benign positional vertigo: incidence and prognosis in a population-based study in Olmsted County, Minnesota. Mayo Clin Proc 1991;66(6):596-601

48. Oghalai JS, Manolidis S, Barth JL, Stewart MG, Jenkins HA. Unrecognized benign paroxysmal positional vertigo in elderly patients. Otolaryngol Head Neck Surg 2000;122(5): 630-634

49. Baloh RW, Honrubia V, Jacobson K. Benign positional vertigo: clinical and oculographic features in 240 cases. Neurology 1987;37(3):371-378

50. Imai T, Ito M, Takeda N, et al. Natural course of the remission of vertigo in patients with benign paroxysmal positional vertigo. Neurology 2005;64(5):920-921

51. Brandt T, Huppert D, Hecht J, Karch C, Strupp M. Benign paroxysmal positioning vertigo: a longterm follow-up (6-17 years) of 125 patients. Acta Otolaryngol 2006;126(2): 160-163

52. Nunez RA, Cass SP, Furman JM. Short- and long-term outcomes of canalith repositioning for benign paroxysmal positional vertigo. Otolaryngol Head Neck Surg 2000;122(5): 647-652

53. Gordon CR, Levite R, Joffe V, Gadoth N. Is posttraumatic benign paroxysmal positional vertigo different from the idiopathic form? Arch Neurol 2004;61(10):1590-1593

54. Karlberg M, Hall K, Quickert N, Hinson J, Halmagyi GM. What inner ear diseases cause benign paroxysmal positional vertigo? Acta Otolaryngol 2000;120(3):380-385

55. Katsarkas A. Benign paroxysmal positional vertigo (BPPV): idiopathic versus post-traumatic. Acta Otolaryngol 1999; 119(7):745-749

56. Vibert D, Kompis M, Häusler R. Benign paroxysmal positional vertigo in older women may be related to osteoporosis and osteopenia. Ann Otol Rhinol Laryngol 2003;112(10):885-889

57. Cohen HS, Kimball KT, Stewart MG. Benign paroxysmal positional vertigo and comorbid conditions. ORL J Otorhinolaryngol Relat Spec 2004;66(1):11-15

58. Lopez-Escamez JA, Gamiz MJ, Fernandez-Perez A, Gomez-Fin ana M. Long-term outcome and health-related quality of life in benign paroxysmal positional vertigo. Eur Arch Otorhinolaryngol 2005;262(6):507-511

59. Dieterich M, Brandt T. Episodic vertigo related to migraine (90 cases): vestibular migraine? J Neurol 1999;246(10):883- 892

60. Headache Classification Subcommittee of the International Headache Society. The International Classification of Headache Disorders: 2nd edition. Cephalalgia 2004;24(Suppl 1): 9-160

61. Cass SP, Furman JM, Ankerstjerne K, Balaban C, Yetiser S, Aydogan B. Migraine-related vestibulopathy. Ann Otol Rhinol Laryngol 1997;106(3):182-189

62. Vukovic' V, Plavec D, Galinovic' I, Lovrencic'-Huzjan A, Budisic' M, Demarin V. Prevalence of vertigo, dizziness, and migrainous vertigo in patients with migraine. Headache 2007;47(10):14271435

63. Kelman $\mathrm{L}$, Tanis $\mathrm{D}$. The relationship between migraine pain and other associated symptoms. Cephalalgia 2006;26(5): 548-553

64. Neuhauser $\mathrm{H}$, Lempert T. Vertigo and dizziness related to migraine: a diagnostic challenge. Cephalalgia 2004;24(2): 83-91

65. Jensen R, Stovner LJ. Epidemiology and comorbidity of headache. Lancet Neurol 2008;7(4):354361

66. Slater R. Benign recurrent vertigo. J Neurol Neurosurg Psychiatry 1979;42(4):363-367

67. Cha YH, Lee H, Santell LS, Baloh RW. Association of benign recurrent vertigo and migraine in 208 patients. Cephalalgia 2009;29(5):550-555

68. Abu-Arafeh I, Russell G. Paroxysmal vertigo as a migraine equivalent in children: a populationbased study. Cephalalgia 1995;15(1):22-25, discussion 4

69. Erbek SH, Erbek SS, Yilmaz I, et al. Vertigo in childhood: a clinical experience. Int J Pediatr Otorhinolaryngol 2006;70(9): 1547-1554

70. Neuhauser H, Radtke A, von Brevern M, Lempert T. Zolmitriptan for treatment of migrainous vertigo: a pilot randomized placebo-controlled trial. Neurology 2003;60(5): 882-883

71. Guilemany J-M,Martín nez P, Prades E, Sañudo I, De España R, Cuchi A. Clinical and epidemiological study of vertigo at an outpatient clinic. Acta Otolaryngol 2004;124(1):49-52

72. Hanley K, O' Dowd T. Symptoms of vertigo in general practice: a prospective study of diagnosis. Br J Gen Pract 2002;52(483):809-812

73. Sekitani T, Imate Y, Noguchi T, Inokuma T. Vestibular neuronitis: epidemiological survey by questionnaire in Japan. Acta Otolaryngol Suppl 1993;503:9-12

74. Huppert D, Strupp M, Theil D, Glaser M, Brandt T. Low recurrence rate of vestibular neuritis: a long-term follow-up. Neurology 2006;67(10):1870-1871 
75. Okinaka Y, Sekitani T, Okazaki H, Miura M, Tahara T. Progress of caloric response of vestibular neuronitis. Acta Otolaryngol Suppl 1993;503:18-22

76. Godemann F, Siefert K, Hantschke-Brüggemann M, Neu P, Seidl R, Ströhle A. What accounts for vertigo one year after neuritis vestibularis - anxiety or a dysfunctional vestibular organ? J Psychiatr Res 2005;39(5):529-534

77. Godemann F, Linden M, Neu P, Heipp E, Dörr P. A prospective study on the course of anxiety after vestibular neuronitis. J Psychosom Res 2004;56(3):351-354

78. Taborelli G, Melagrana A, D'Agostino R, Tarantino V, Calveo MG, Calevo . Vestibular neuronitis in children: study of medium and long term follow-up. Int J Pediatr Otorhinolaryngol 2000;54(2-3):117-

121

79. Kotimäki J, Sorri M, Aantaa E, Nuutinen J. Prevalence of Meniere disease in Finland. Laryngoscope 1999;109(5): 748-753

80. Wladislavosky-Waserman P, Facer GW, Mokri B, Kurland LT. Meniere's disease: a 30-year epidemiologic and clinical study in Rochester, Mn, 1951-1980. Laryngoscope 1984; 94(8):1098-1102 81. Ballester $M$, Liard $P$, Vibert $D$, Häusler R. Menière's disease in the elderly. Otol Neurotol 2002;23(1):73-78

82. Vrabec JT, Simon LM, Coker NJ. Survey of Menière's disease in a subspecialty referral practice. Otolaryngol Head Neck Surg 2007;137(2):213-217

83. Cha YH, Brodsky J, Ishiyama G, Sabatti C, Baloh RW. The relevance of migraine in patients with Menière's disease. Acta Otolaryngol 2007;127(12):1241-1245

84. Cha YH, Kane MJ, Baloh RW. Familial clustering of migraine, episodic vertigo, and Menière's disease. Otol Neurotol 2008;29(1):93-96

85. Derebery MJ, Berliner KI. Prevalence of allergy in Meniere's disease. Otolaryngol Head Neck Surg 2000;123(1 Pt 1):69-75 
Table 1 Prevalence and Incidence of Dizziness and Vertigo of Moderate/Severe Intensity in the General Adult Population

Based on data from Neuhauser et al.12

\begin{tabular}{|c|c|c|c|c|c|c|}
\hline & \multicolumn{6}{|c|}{ Population } \\
\hline & Women \% & $95 \% \mathrm{Cl}$ & Men \% & $95 \% \mathrm{Cl}$ & Total $\%$ & $95 \% \mathrm{Cl}$ \\
\hline \multicolumn{7}{|l|}{ Incidence (1 year) } \\
\hline Dizziness/vertigo & 4.0 & $3.2-5.0$ & 2.3 & $1.6-3.1$ & 3.1 & $2.6-3.8$ \\
\hline Vestibular vertigo & 1.9 & $1.4-2.7$ & 0.8 & $0.4-1.3$ & 1.4 & $1.0-1.8$ \\
\hline \multicolumn{7}{|l|}{ Prevalence (1 year) } \\
\hline Dizziness/vertigo & 28.9 & $26.8-31.1$ & 16.7 & $15.0-18.6$ & 22.9 & $21.5-24.3$ \\
\hline Vestibular vertigo & 7.1 & $6.0-8.4$ & 2.6 & $1.9-3.5$ & 4.9 & $4.2-5.7$ \\
\hline \multicolumn{7}{|l|}{ Prevalence (lifetime) } \\
\hline Dizziness/vertigo & 35.9 & $33.7-38.3$ & 22.6 & $20.6-24.7$ & 29.3 & $27.8-30.9$ \\
\hline Vestibular vertigo & 10.3 & $9.0-11.8$ & 4.3 & $3.4-5.4$ & 7.4 & $6.5-8.3$ \\
\hline
\end{tabular}

Figure 1 Twelve-month prevalence of vestibular vertigo in adults. (Based on data from Neuhauser et al.11)

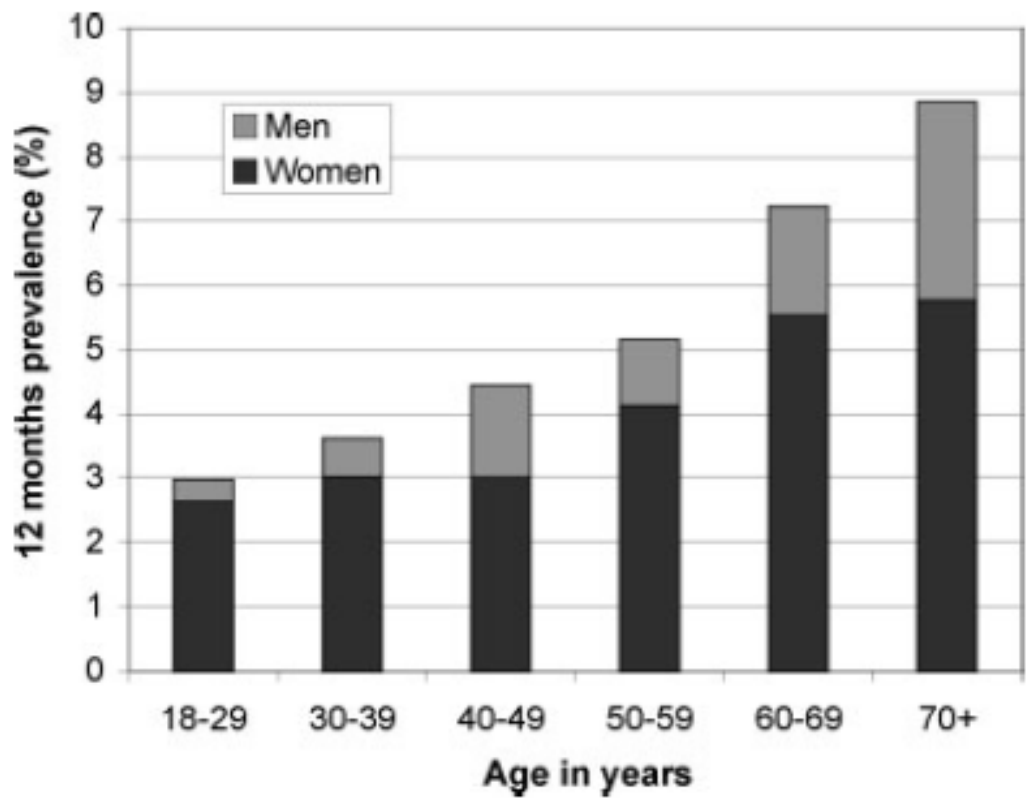

